\title{
Comparison of hospital worker anxiety in COVID-19 treating and non-treating hospitals in the same city during the COVID-19 pandemic
}

\author{
Yael Milgrom ${ }^{1 *}$ (D, Yuval Tal ${ }^{2}$ and Aharon S. Finestone ${ }^{3}$
}

\begin{abstract}
Background: The Hadassah Medical Organization operates two hospitals in Jerusalem. During the COVID-19 pandemic it made an administrative decision to operate one hospital as a COVID-19 treatment hospital (CTH) and to have the second function as a non-COVID-19 treating hospital (NCTH) offering general medical services. The purpose of this study was to assess how this decision affected hospital worker anxiety.

Methods: From April 27 to May 1, during the COVID-19 pandemic in Israel, while the country was under lockdown, an electronic questionnaire survey was carried out among hospital workers of the CTH and NCTH. The questionnaire includes personal demographics and attitudes about COVID-19 and assesses present anxiety state using the State-Trait Anxiety Inventory for Adults (STAI-S) validated questionnaire. A STAI-S score of $\geq 45$ was considered to represent clinical anxiety.

Results: Completed questionnaires were received from 1570 hospital employees (24\%). 33.5\% of responders had STAI-S scores $\geq 45$. Multivariable regression analysis showed that being a resident doctor (odds ration [OR] 2.13; 95\% $C L, 1.41-3.23 ; P=0.0003)$, age $\leq 50(\mathrm{OR}, 2.08 ; 95 \% \mathrm{Cl}, 1.62-2.67 ; P<.0001)$, being a nurse $(\mathrm{OR}, 1.29 ; 95 \% \mathrm{CL}, 1.01-$ $1.64 ; P=0.039)$, female gender $(\mathrm{OR}, 1.63 ; 95 \% \mathrm{CL}, 1.25-2.13 ; P=0.0003)$ and having risk factors for COVID-19 (OR, $1.51 ; 95 \% C L, 1.19-1.91 ; P=0.0007)$, but not hospital workplace $(p=0.08)$, were associated with the presence of clinical anxiety. $69 \%$ of the responders had been tested for COVID-19, but only nine were positive. CTH workers estimated that the likelihood of their already being infected with COVID-19 to be $21.5 \pm 24.7 \%$ as compared to the $15.3 \pm 19.5 \%$ estimate of NCTH workers ( $p=0.0001) .50 \%$ (545/1099) of the CTH workers and $51 \%(168 / 330)$ of the $\mathrm{NCTH}$ workers responded that the most important cause of their stress was a fear of infecting their families $(p=0.7)$. Conclusions: By multivariable analysis the creation of a NCTH during the COVID-19 pandemic was not found to be associated with a decrease in the number of hospital workers with clinical anxiety. Hospital worker support resources can be focused on the at-risk groups identified in this study.
\end{abstract}

Keywords: Anxiety, COVID-19 pandemic, Questionnaire, Risk factors, Lock-down, Hospital workers

\footnotetext{
* Correspondence: yaelmil@hadassah.org.il

'The Liver Unit, Internal Medicine, Hadassah University Hospital, Ein Kerem, 911200 Jerusalem, Israel

Full list of author information is available at the end of the article
}

C C The Author(s). 2020 Open Access This article is licensed under a Creative Commons Attribution 4.0 International License, which permits use, sharing, adaptation, distribution and reproduction in any medium or format, as long as you give appropriate credit to the original author(s) and the source, provide a link to the Creative Commons licence, and indicate if changes were made. The images or other third party material in this article are included in the article's Creative Commons licence, unless indicated otherwise in a credit line to the material. If material is not included in the article's Creative Commons licence and your intended use is not permitted by statutory regulation or exceeds the permitted use, you will need to obtain permission directly from the copyright holder. To view a copy of this licence, visit http://creativecommons.org/licenses/by/4.0/ The Creative Commons Public Domain Dedication waiver (http://creativecommons.org/publicdomain/zero/1.0/) applies to the data made available in this article, unless otherwise stated in a credit line to the data. 


\section{Background}

The World Health Organization (WHO) declared the COVID-19 virus to be a public health emergency on January 20, 2020. Soon afterward, on March 11, the WHO re-classified the problem as a pandemic.

The WHO published an interim guidance on March 4, 2020 entitled "Health workers exposure risk assessment and management in the context of COVID-19 virus" [1]. A subsequent WHO interim guidance from March 19, 2020 [2], emphasized that the COVID-19 pandemic inevitably places health care workers at risk.

In view of the challenges of treating patients possibly infected with COVID-19 as well as those documented with the disease, exposed health care workers can be psychologically stressed [3-8]. A study from China reported depression in $50 \%$ and anxiety in $45 \%$ of nurses and physicians in the epicenter of the pandemic, the city of Wuhan, versus $7.2 \%$ in less affected regions of China [9]. Within the healthcare system it is the hospital which is the most affected by the COVID-19 pandemic.

COVID-19 is the second pandemic of the twenty-first century. The first was the influenza $\mathrm{A} / \mathrm{H} 1 \mathrm{~N} 1$ virus infection, also known as swine flu in 2009. It differed from the COVID-19 pandemic in that the A/H1N1-09 virus survival time is greatly affected by seasonal temperatures, many older people already had immunity through exposure to similar viruses in the past and by the end of 2009 an effective vaccine was available. Hospital staff worries during that previous pandemic have been reported [10]. Twenty-one percent of the hospital staff were reported as having mild to moderate psychological distress, with the highest rate (23.9\%) among nurses and the lowest rate (12.3\%) among auxiliary personnel. The most frequent concern of staff was infection of family and friends and the health consequences of the disease, but only $6.6 \%$ of hospital workers restricted their social contacts. Around 3 billion doses of H1N1-09 vaccine were produced and many of them discarded due to low demand. During the SARS outbreak in 2003 in Toronto, 43\% of the infected people were health care workers [11, 12]. Protective gear was required for health care workers and socialization in the hospital was restricted. The present COVID-19 pandemic is different in its epidemiology and in the fact that full population lock-downs were used in an attempt to control the pandemic.

During the first wave of the COVID-19 pandemic in Israel the Hadassah Medical Organization made an administrative decision to operate one of its two hospitals in Jerusalem as a COVID-19 treating hospital (CTH) and the other to be a non-COVID-19 treating hospital $(\mathrm{NCTH})$, The NCTH continued to offer general medical services, doing elective procedures and surgery. A hospital by nature is a closely knit environment in which the efforts and coordination of all types of workers, both medical and non-medical are needed to provide good health care. During medical emergencies this interdependence is even more pronounced. The purpose of the present study was to assess the effect of the decision to create a CTH and a NCTH during the first wave of the COVID-19 pandemic on the level of clinical anxiety among all of the components of the workforce between the two hospitals. The findings can be informative for decision making during the current second and possible future waves of the pandemic. The authors hypothesized that CTH workers would have a higher percentage of clinical anxiety than NCTH workers.

\section{Methods}

The Hadassah Medical Organization has two hospitals in Jerusalem. One hospital is located at Ein Kerem in the western part of the city and is an 800-bed level-3 hospital. The second hospital is located at Mt Scopus in the eastern part of the city and is a 300-bed level-2 hospital. During the height of the first wave of the COVID-19 pandemic, the Hadassah Medical Organization decided that the level-3 hospital would suspend all elective procedures and operations and function as a COVID-19 treating hospital $(\mathrm{CTH})$. Services included dedicated COVID-19 wards for mild and moderate patients, ICU units for severe patients and a COVID-19 emergency room. The level-2 hospital was kept functioning as a non-COVID-19 hospital (NCTH), providing general medical services and continued to perform elective procedures and operations. While it had a separate emergency room for screening any patient suspected of having COVID-19, all patients diagnosed with COVID19 were transferred to the $\mathrm{CTH}$.

After receiving institutional review board approval (0281-20-HMO), a pilot was done to check that the electronic questionnaire was clear and that the automatic recording system worked properly. After necessary adjustments were made, a link to the electronic questionnaire was sent by hospital internal email and also to the mobile phones of each of the $\mathrm{CTH}$ and $\mathrm{NCTH}$ workers between April 27-30. Responses were accepted only until noon on May 1. Replies received afterwards were not included in the analysis because government plans to end some of the provisions of the COVID-19 lock-down were announced at that time. The questionnaire is anonymous and the details were automatically sent to an Excel spreadsheet (Microsoft Corp. Redmond, WA.) using Google Forms (Google Mountain View, CA).

The questionnaire has two parts. The first part is a survey of personal demographics and a questionnaire about specific issues related to COVID-19. The survey is presented in Table 1.

The second part of the questionnaire is a validated Hebrew translation of the 20-question portion of the 
Table 1 The personal demographics questionnaire

\author{
1. Gender: \\ 2. Age: \\ 3. Who lives in your household? \\ 4. In which hospital do you work? \\ 5. What is your position in the hospital?
}

6. In what department do you work?

7. Are you on a COVID-19 Department team?

8. Are you currently working?

9. The following are risk factors for COVID-19. Do you suffer from any of them?

10. Have you been in isolation because of the COVID19 ?

11. Have you have been tested for COVID-19?

12. What were the COVID-19 test result?

13. Did you feel relieved after getting tested?

13. Of all of the following, which is of the most concern?

14. Of the following, which would make the corona epidemic easier for you?

15. What percentage do you estimate that you

already have gotten the corona virus?

State-Trait Anxiety Inventory for Adults (STAI-S) assessing anxiety state [13]. The S-Anxiety scale requires that the participant describe how he or she feels "now, at the present moment". The scoring weight for the 10 anxiety present questions is: 1- Absolutely not; 2- A little; 3Much; 4- Very Much. The scoring weight for the 10 anxiety absent questions is reversed. The total score varies from 20 to 80 , and the higher the values, the greater the anxiety level. The questions composing the STAI-S are presented in Table 2 . There are no published specific normative STAI-S values for hospital staff. Values are available for college students $(36.47 \pm 10.01$ for males and $38.77 \pm 11.90$ for females), [13]. Bunevicius et al. [14], in their study of cardiac patients considered the cut-off value to represent clinical anxiety to be $\geq 45$. When tested against other known measures for clinical anxiety they found that the STAI-S had a sensitivity of $89 \%$ and a specificity of $56 \%$. The Bunevicius et al. [14] criteria were used in this study, with a score of $\geq 45$ was considered to represent clinical anxiety [14].

\section{Statistical analysis}

Statistical analysis was performed using the Statistical Analysis System (SAS Institute Inc., Cary, North Carolina, USA, version 9.4). Normally distributed interval data were compared across the groups, using the 2-tail Student's t-test. Comparison of non parametric data was
Table 2 The questions composing the State-Trait Anxiety Inventory for Adults (STAI-S)

\begin{tabular}{ll}
\hline STAI-S & \\
\hline Question Number & Question \\
\hline 1 & | feel calm \\
3 & | feel secure \\
4 & | am tense \\
5 & | feel strained \\
6 & | feel at ease \\
7 & | feel upset \\
8 & | am presently worried about possible misfortune \\
9 & | feel satisfied \\
10 & | feel frightened \\
11 & | feel comfortable \\
12 & | feel self confident \\
13 & | feel nervous \\
14 & | am jittery \\
15 & | feel indecisive \\
16 & | am relaxed \\
17 & | feel content \\
18 & | am worried \\
19 & | feel confused \\
20 & | feel steady \\
\hline & | feel pleasant \\
\hline
\end{tabular}


done using the Mann-Whitney $U$ test. Nominal data were assessed with the chi-square test and Fischer's exact test. Multivariable analysis to determine potential risk factors for increased STAI-S scores was performed using the generalized linear model (GLM) procedure. Variables measured by univariable analysis with $p<0.05$ were entered into the model. In addition, stepwise multivariable logistic regression was performed to determine risk factors for clinical anxiety based on those with STAI-S scores $\geq 45$. The association between risk factors and outcomes are presented as odds ratios (ORs) and 95\% CLs after adjustment for confounders. Hospital, resident doctor, senior doctor, nurse, administrative staff, age $\geq 50$, gender, presence of risk factors for COVID-19 and parents in the household were entered into the model. Data for employees who worked at both centers was excluded for any analysis that compared the CTH with the $\mathrm{NCTH}$. To assess possible study sample size bias a comparison of major demographic variables of the surveyed study population and available total workforce data for each hospital was performed.

\section{Results}

Complete questionnaires were received from 1570 of the 6528 hospital employees (24\%). The mean total STAI-S score for all of the workers was $42.4 \pm 11.8$. $33.5 \%$ of the workers had STAT-S scores $\geq 45$ indicating the presence of clinical anxiety. Table 3 presents the mean \pm SD, median and interquartile range (IQR) and the percentage of those with STAI-S scores $\geq 45$ according to worker categories. The highest anxiety scores were among dentists and resident doctors and the lowest among senior doctors.
By univariate analysis, overall workers at the CTH had a higher mean STAI-S score $(43 \pm 11.7)$ than workers at the NCTH $(40.8 \pm 11.8),[p=0.005]$. The percentage of overall CTH workers (35\%) with STAI-S scores $\geq 45$ was higher than the percentage of overall NTCH workers ((29\%) who had STAI-S scores $\geq 45$, but these differences were not supported by multivariable analysis. Differences in the STAI-S scores between the two hospitals for any of the individual worker categories were not statistically significant by univariate analysis.

The mean and $\geq 45$ State-Trait Anxiety Inventory (STAI-S) scores of the hospital workers were further analyzed using univariable analysis according to the demographic data collected from the questionnaire. Table 4 presents these analyses according to major demographic groupings.

Thirty-two point six percent of the workers had risk factors for COVID-19. Nine of the 1082 hospital workers who reported that they had taken a COVID-19 test stated that the test was positive. Administrative hospital data compiled at the time of the study showed that 38 workers had positive COVID-19 tests, 28 from the CTH and 10 from the NCTH. Workers at the CTH estimated that the likelihood of their already being infected with COVID-19 to be $21.5 \pm 24.7 \%$. This was significantly higher than the $15.3 \pm 19.5 \%$ estimation of the NCTH workers $(p=0.0001) .43 \% \quad(474 / 1093)$ of the CTH workers and $46.5 \%(138 / 297)$ of NCTH hospital workers responded that the most important stress reliever was better protective gear $(p=0.3) .17 \%(190 / 1093)$ of the CTH workers and $18 \%(54 / 297)$ of the NCTH workers responded that the most important stress reliever was a

Table 3 State-Trait Anxiety Inventory (STAI-S) scores according to major worker categories

\begin{tabular}{lllll}
\hline Worker Category & No. & Mean \pm SD & Median (IQR) & \% STAI-S $\geq \mathbf{4 5}$ \\
\hline Dentists & 13 & $47.9 \pm 12.9$ & $49(36-52)$ & $53.8 \%$ \\
Resident doctors & 117 & $46.3 \pm 12.2$ & $47(37-56)$ & $48.7 \%$ \\
Others & 54 & $42.0 \pm 11.9$ & $41(35-50)$ & $38.9 \%$ \\
Nurses & 487 & $44.2 \pm 11.9$ & $43(35.5-53)$ & $37.9 \%$ \\
Research staff & 58 & $43.3 \pm 11.9$ & $45(35-52)$ & $37.9 \%$ \\
Office staff & 234 & $42.4 \pm 11.7$ & $42(33.5-52)$ & $33.6 \%$ \\
Physician Assist. & 10 & $37.5 \pm 12.0$ & $37(27-46)$ & $30.0 \%$ \\
Lab workers & 93 & $42.4 \pm 10.6$ & $43(34-50)$ & $29.0 \%$ \\
Social workers/ psychologists & 42 & $42.2 \pm 9.7$ & $41(35-50)$ & $28.5 \%$ \\
Non-physician clinicians & 75 & $40.6 \pm 11.0$ & $39(33.5-46.5)$ & $28.0 \%$ \\
General service & 62 & $40.2 \pm 11.0$ & $39(33-49)$ & $27.4 \%$ \\
Interns & 18 & $38.4 \pm 12.0$ & $43(27-47)$ & $27.7 \%$ \\
Technicians & 75 & $40.9 \pm 11.3$ & $40(33-48)$ & $25.3 \%$ \\
Senior doctors & 220 & $38.0 \pm 11.8$ & $36(28-46)$ & $23.6 \%$ \\
Pharmacists & 12 & $38.9 \pm 7.2$ & $41(37-44)$ & $8.3 \%$ \\
All staff & 1570 & $42.4 \pm 11.8$ & $3.5 \%$ & 31 (34-51) \\
\hline
\end{tabular}


Table 4 Mean and $\geq 45$ STAI-S scores of workers according to major demographic variables

\begin{tabular}{|c|c|c|c|c|c|}
\hline Group & No. & Median STAI-S (IQR) & $P$ value & $\%$ STAI-S $\geq 45$ & $P$ value \\
\hline $\mathrm{CTH}$ & 1213 & $42(34-52)$ & 0.005 & $34.8 \%$ & 0.04 \\
\hline $\mathrm{NCTH}$ & 340 & $40(31-49)$ & & $28.8 \%$ & \\
\hline Males & 442 & $38(30-48)$ & 0.0001 & $26.9 \%$ & 0.0008 \\
\hline Females & 1125 & $43(35-52)$ & & $35.8 \%$ & \\
\hline Medical risk factors & 512 & $43(34-50)$ & 0.03 & $36.7 \%$ & 0.006 \\
\hline No medical risk factors & 1052 & $41(33-50)$ & & $29.9 \%$ & \\
\hline Tested for COVID-19 & 1082 & $42(34-51)$ & 0.13 & $34.6 \%$ & 0.1 \\
\hline Not tested & 480 & $41(33-50)$ & & $30.6 \%$ & \\
\hline Quarantined & 201 & $42(34-53)$ & 0.55 & $32.3 \%$ & 0.7 \\
\hline Not quarantined & 1360 & $42(34-51)$ & & $33.5 \%$ & \\
\hline Age $>50$ & 485 & $37.5(29-47)$ & 0.0001 & $23.2 \%$ & 0.0001 \\
\hline Age $<50$ & 1064 & $43(35-53)$ & & $38.6 \%$ & \\
\hline Senior doctors & 220 & $36(28-48)$ & 0.0001 & $23.6 \%$ & 0.0001 \\
\hline Resident doctors & 120 & $46.5(36-56)$ & & $48.3 \%$ & \\
\hline Nurses & 466 & $43(35-53)$ & 0.0002 & $38.0 \%$ & 0.0007 \\
\hline Non-nurses & 1088 & $41(33-50)$ & & $29.5 \%$ & \\
\hline Have children & 929 & $42(33-51)$ & 0.3 & $33.1 \%$ & 0.3 \\
\hline No children & 708 & $43(34-52)$ & & $30.7 \%$ & \\
\hline Parent in household & 162 & $45(37-52)$ & 0.02 & $42.0 \%$ & 0.004 \\
\hline No parent in household & 1475 & $42(33-51)$ & & $30.9 \%$ & \\
\hline
\end{tabular}

permanent arrangement for their children $(p=0.7) .50 \%$ (545/1099) of the CTH workers and 51\% (168/330) of the NCTH workers responded that the most important cause of their stress was a fear of infecting their families $(p=0.7)$.

By multivariable analysis higher STAI-S scores were found to be associated with CTH hospital $(p=0.005)$, female gender $(p=0.001)$, age $\leq 50(p=0.001)$, those with risk factors for COVID-19 ( $p=0.001)$, being a resident doctor $(p=0.001)$ and being a nurse $(p=0.001)$.

The results of stepwise multivariable regression analysis performed to identify risk factors for clinical anxiety as defined by STAI-S scores $\geq 45$ is presented in Table 5 .. Working in the COVID-19 treating hospital was not found to be a significant factor by this analysis.

Demographic data for the total workforces of the CTH and NCTH were obtained from the Office of Manpower of the Hadassah Medical Organization and from

Table 5 Risk factors for hospital staff clinical anxiety according to multivariable regression analysis

\begin{tabular}{lll}
\hline Variable & Odds Ratio $(95 \% \mathrm{Cl})$ & $\boldsymbol{P}$ value \\
\hline Resident doctor & $2.13(1.41-3.23)$ & 0.0003 \\
Age $\leq 50$ years & $2.08(1.62-2.67)$ & $<.0001$ \\
Nurse & $1.29(1.01-1.64)$ & 0.0399 \\
Female & $1.63(1.25-2.13)$ & 0.0003 \\
Having risk factors for COVID-19 & $1.51(1.19-1.91)$ & 0.0007 \\
\hline
\end{tabular}

published control reports. The surveyed population was not statistically different from the general population of each hospital for the percentage of nurses, senior doctors, resident doctors, and those age $\leq 50$ years. There was a difference in the percentage of females in the $\mathrm{CTH}$ compared to the CTH survey population, but not for the NCTH. Table 6 presents this comparison data. We were unable to obtain risk factor data for COVID-19 for the total workforce.

\section{Discussion}

The hypothesis that a higher percentage of $\mathrm{CTH}$ workers would have clinical anxiety than NCTH workers was not found to be true in this study. While the univariate analysis suggests that a higher percentage of workers in the $\mathrm{CTH}$ than in the NCTH had clinical anxiety according to STAI-S scores $\geq 45$ [14], this difference was not supported by multivariable analysis. When specific categories of workers were analyzed for the effect of working in the two hospitals on their mean anxiety and the percentage with clinical anxiety, no differences were found. This was also true for resident doctors and nurses who in the CTH were on the frontline of COVID-19 treatment.

Why the creation of a NCTH did not result in a lower level of worker clinical anxiety can have several possible explanations, some of which are intrinsic and some extrinsic to the hospital. First of all, the creation of a 
Table 6 Comparison of the percentage of workers of the surveyed population and total hospital workforce data of each hospital according to demographic variables

\begin{tabular}{|c|c|c|c|c|c|c|}
\hline \multirow[t]{3}{*}{ Variable } & \multicolumn{6}{|c|}{ Percentage of Worker Population } \\
\hline & \multicolumn{3}{|l|}{$\overline{\mathrm{CTH}}$} & \multicolumn{3}{|l|}{ NCTH } \\
\hline & Survey Population & Total Population & $P$ value & Survey Population & Total Population & $P$ value \\
\hline Nurses & $\begin{array}{l}136 \\
(\mathbf{4 0 \% )}\end{array}$ & $\begin{array}{l}479^{a} \\
\text { (39.1\%) }\end{array}$ & 0.41 & $\begin{array}{l}349 \\
\text { (28.8\%) }\end{array}$ & $\begin{array}{l}1859^{b} \\
(\mathbf{3 1 . 3} \%)\end{array}$ & 0.08 \\
\hline Senior Physicians & $\begin{array}{l}45 \\
(13.2 \%)\end{array}$ & $\begin{array}{l}123^{\mathrm{a}} \\
(\mathbf{1 0 \%} \%)\end{array}$ & 0.69 & $\begin{array}{l}166 \\
(13.7 \%)\end{array}$ & $\begin{array}{l}717^{b} \\
(12.1 \%)\end{array}$ & 0.12 \\
\hline Resident Physicians & $\begin{array}{l}25 \\
(7.4 \%)\end{array}$ & $\begin{array}{l}71^{\mathrm{a}} \\
(5.8 \%)\end{array}$ & 0.49 & $\begin{array}{l}91 \\
(7.5 \%)\end{array}$ & $\begin{array}{l}540^{\mathrm{b}} \\
\mathbf{( 9 . 1 \% )}\end{array}$ & 0.07 \\
\hline Female & $\begin{array}{l}248 \\
\text { (72.9\%) }\end{array}$ & $\begin{array}{l}1007^{c} \\
(\mathbf{7 0 \% )}\end{array}$ & 0.28 & $\begin{array}{l}870 \\
\text { (71.7\%) }\end{array}$ & $\begin{array}{l}3215^{c} \\
\mathbf{( 6 3 . 2 \% )}\end{array}$ & 0.0001 \\
\hline Age $\leq 50$ & $\begin{array}{l}215 \\
\text { (63.2\%) }\end{array}$ & $\begin{array}{l}977^{c} \\
(67.9 \%)\end{array}$ & 0.1 & $\begin{array}{l}861 \\
\text { (71\%) }\end{array}$ & $3623^{c}(\mathbf{7 1 . 2 \% )}$ & 0.88 \\
\hline Denominator & 340 & $\begin{array}{l}a_{1126} \\
c_{1439}\end{array}$ & & 1213 & $\begin{array}{l}b_{5930} \\
c_{5089}\end{array}$ & \\
\hline
\end{tabular}

${ }^{a}$ Control Report Hadassah University Hospital Mt Scopus (06/06/2018). https://www.health.gov.il/PublicationsFiles/HadasaHZ 06062018.pdf

${ }^{b}$ Control Report Hadassah University Hospital Ein Kerem (11/04/2018). https://www.health.gov.il/PublicationsFiles/HADASA_EC_11042018.pdf

'Office of Manpower Hadassah Medical Organization

NCTH might not have been equated by the hospital staff to mean that it was coronavirus free. The possibility of $\mathrm{NCTH}$ staff contact with patients carrying the coronavirus in the emergency room existed. There also was the possibility of exposure to patients who were admitted to the hospital with undiagnosed COVID-19. Another explanation may be that the anxiety caused by the population lock-down was a more dominant factor in causing hospital worker anxiety than factors intrinsic to their hospital workplace. The results could also have been affected by sample bias due to the survey low response rate.

To check for possible sample bias a comparison was done between the surveyed population and total workforce data from each hospital. The variables nurses, senior doctors, resident doctors, those of age $\leq 50$ years and female gender were assessed. Statistical analysis showed that the surveyed population was not different from the general population of each hospital for the percentage of nurses, senior doctors, resident doctors, and those age $\leq 50$ years. There was a difference in the percentage of females in the CTH compared to the CTH survey population, but not for the NCTH. This analysis indicates that the likelihood of study sample bias is low.

Lai et al. [9], reported on the mental health outcomes among nurses and physicians exposed to COVID-19 in the hospitals of Wuhan China during the pandemic. The nurses and physicians in Wuhan, who were part of the Lai et al. [9] study, were in an environment similar to that of the hospital workers in the current study in that both were working in an environment of a COVID-19 pandemic lock-down. In their study, they found by multivariable analysis that frontline health care workers engaged in direct diagnosis, treatment and care of patients with COVID-19 had a higher risk for symptoms of anxiety, insomnia and distress. In the current study using multivariable analysis, there was no significant difference found in the percentage of workers with clinical anxiety in the $\mathrm{CTH}$, which was frontline and workers in the $\mathrm{NCTH}$ which was not frontline. Among those on the front-lines Lai et al. [9] 50.4\% suffered from depression, $44.6 \%$ from anxiety and 71.5 from insomnia. Similar levels of those with clinical anxiety were found in this study, with $49 \%$ of resident doctors and nurses having clinical anxiety. That the senior doctors in this study were on the opposite end of the clinical anxiety spectrum with $24 \%$ effected, may reflect their experience in confronting crises medical crises and/or less involvement in direct patient care. This study differs from the Chinese study [9] in that it was done in a country with a different governmental system and where the COVID-19 pandemic was considered at the time of the study to be under control. At the time when this study was performed, less than 200 people had died and 16,000 had been diagnosed in a country with a population of 9.1 million.

The study of Giulia et al. [10] of psychological distress in a single Greek tertiary teaching hospital during the swine flu pandemic took place in a social system closer to the present study than in the Lai et al. study [9]. They found that the degree of anxiety and perceived risk of infection were both moderately high among health care workers. There however were no reported deaths in their hospital from swine flu during their study." Two years after the SARS outbreak in Toronto, Maunder et al. [15] reported that health care workers who treated SARS patients had elevated rates of signs of chronic stress than workers who did not treat SARS patients.

This study identified hospital workers at risk for clinical anxiety in the COVID-19 pandemic. By multivariable analysis being a medical resident, age $\leq 50$ years, 
being a nurse, female gender and workers with risk factors for COVID-19 were all found to be risk factors and odds ratios were calculated for each. This information is important because it can help focus administrative support to high risk groups among hospital workers during future waves of COVID-19 or other future pandemics.

While $69 \%$ of the hospital workers in this study had been tested for COVID-19, only nine tested positive for COVID-19. The low rate of infection (6.7/1000 workers) based on the data from the questionnaire is similar to the rate (5.4/1000 workers) calculated from the data compiled by medical organization administration. It reflects the fact that the lesson of having good protective gear available for the hospital staff was learned from the counties effected earlier in the pandemic. Forty-four percent of the workers in this study indicated that having good protective gear relieved their stress.

The workers in the CTH estimated that they had a $21 \%$ chance of having already contracted COVID-19 as opposed to the $15 \%$ estimate of NCTH workers $(p=$ 0.0001). This is in spite of the high number of workers who had polymerase chain reaction tests. It reflects the knowledge of the hospital workers that having a single negative polymerase chain COVID-19 test does not mean conclusively that a person does not, or did not have COVID-19.

A weakness of this study is the relatively low percentage of responders to the questionnaire. This can result in study bias and possibly over estimate anxiety. The low response rate is a function of the fact that the survey was not administered, that data collection was limited to only a 4 day period and that most of the hospital workers were working extra long shifts and opening an electronic message and responding to a questionnaire may not have been a priority for them. In spite of the low response rate, analysis showed that surveyed population was similar to the total workforce population in major demographics. Given these conditions, we believe that the study offers a valuable snapshot assessment of the anxiety and attitudes of hospital workers during the population lock-down stage of the COVID-19 pandemic. It is the largest study cohort to date measuring hospital worker anxiety during the COVID-19 pandemic. It is the only study that compares hospital worker anxiety in COVID-19 treating and non-treating hospitals within the same medical system in the same city. It also surveys the entire hospital staff and not just nurses and doctors.

The current study was done in a COVID-19 pandemic environment, with a population lock-down present. The study hypothesis that CTH workers would have a higher percentage of clinical anxiety than NCTH workers was not found to be true. While not having the hypothesized effect, the administrative designation and operation of a hospital as a non-COVID-treating center allowed it to provide full and needed medical services. The greatest hospital worker concerns found in this study were having good protective gear and not infecting their family. In spite of having an ample supply of good protective gear and being in a country with early and effective national management of the COVID-19 pandemic, one third of the workers in both hospitals had clinical anxiety. This study identified both risk factors for clinical anxiety among hospital workers during the first wave of the COVID-19 pandemic as well as those workers most susceptible. Sustained staff clinical anxiety can have a detrimental effect on worker health and performance. The study findings can be used in decision making to help develop and focus supportive efforts in the current second wave of the pandemic and in possible future waves.

The hospital staff concerns identified in this study can potentially be mitigated by practical steps. One way is for hospitals to provide a safe as possible working environment. This means enforcement of proper patient mask wearing and social distancing between patients and staff. Social distancing should be practiced within the staff as well. Whenever possible staff personal meetings should be conducted remotely. COVID-19 testing should be readily available with a minimum of administrative hassle for both patients and staff. Scheduled routine testing of staff might also serve to decrease anxiety. Hospital management should target, monitor and offer support to high risk worker groups using remote meetings.

Another way to help address the concerns of the hospital staff is to minimize uncertainty by providing regular detailed hospital COVID-19 information at two levels. One level is specific to the staff's own hospital and the other is country wide data. The staff should not learn of their hospitals COVID-19 status by hearsay. Work guidelines for hospital workers who have comorbidities should be published. Online COVID-19 educational courses should be available for nurses, residents and senior doctors who do not ordinarily take care of internal medicine cases to prepare them if needed to treat COVID-19 patients. Sufficient reserve manpower also needs to be available to replace hospital workers who display high levels of clinical anxiety.

\section{Acknowledgements \\ The authors are grateful to Victor Novak of the Clinical Research Center, Soroka University Medical Center and to Avital Savir of the Occupational} Health Unit, Hadassah University Hospital for their professional assistance.

\section{Authors' contributions}

YM designed the study, collected and helped to analyze the data and drafted the first manuscript. YT was responsible for making the questionnaire electronic and was a major contributor in writing the manuscript. ASF was responsible for data analysis. All authors read and approved the final manuscript.

Funding

No specific funding was received for this research. 


\section{Availability of data and materials}

The datasets used and/or analyzed during the current study are available from the corresponding author on reasonable request.

\section{Ethics approval and consent to participate}

This study was approved by the Helsinki Committee of the Hadassah Medical Organization (Hadassah Medical Organization \# 0281-20).

\section{Consent for publication}

Not applicable.

\section{Competing interests}

The authors declare that they have no competing interests.

\section{Author details}

'The Liver Unit, Internal Medicine, Hadassah University Hospital, Ein Kerem, 911200 Jerusalem, Israel. ${ }^{2}$ Occupational Health Unit, Internal Medicine, Hadassah University Hospital, Ein Kerem, Jerusalem, Israel. ${ }^{3}$ Department of Orthopaedics, Shamir Medical Center, Zerifin and Faculty of Medicine, Tel Aviv University, Tel Aviv, Israel.

Received: 10 July 2020 Accepted: 14 October 2020

Published online: 21 October 2020

\section{References}

1. World Health Organization. Health workers exposure and management in the context of COVID-19 virus: interim guidance. Geneva: World Health Organization; 2020. https://apps.who.int/iris/handle/10665/331340. Accessed 4 Mar 2020.

2. World Health Organization. Coronavirus disease (COVID-19) outbreak: rights roles and responsibilities of heath workers, including key considerations for occupational safety and health: interim guidance. Geneva: World Health Organization; 2020. https://apps.who.int/iris/handle/10665/331510. Accessed 19 Mar 2020.

3. Xiang $Y T$, Jin Y, Wang Y, Zhang Q, Zhang L, Cheung T. Tribute to health workers in China: a group of respectable population during the outbreak of the COVID-19. Int J Biol Sci. 2020;16(10):1739-40.

4. Shanafelt T, Ripp J, Trockel M. Understanding and Addressing Sources of Anxiety Among Health Care Professionals During the COVID-19 Pandemic. JAMA. 2020. https://doi.org/10.1001/jama.2020.5893.

5. Silva CGL. When health professionals look death in the eye: the mental health of professionals who deal daily with the 2019 coronavirus outbreak. Psychiatry Res. 2019. https://doi.org/10.1016/.jpsychres.2020.112972.

6. El-Hage W, Hingray C, Lemogne C, Yrondi A, Brunault P, Bienvenu T, et al. Health professionals facing the coronavirus disease 2019 (COVID-19) pandemic: What are the mental health risks? Encephale. 2020. https://doi. org/10.1016/j.encep.2020.04.008.

7. Bohlken J, Schömig F, Lemke MR, Pumberger M, Riedel-Heller SG. COVID-19 pandemic: stress experience of healthcare workers - a short current review. Psychiatr Prax. 2020;47(4):190-7.

8. Neto MLR, Almeida HG, Esmeraldo JD, Nobre C B, Pinheiro WR, et al. When health professionals look death in the eye: the mental health of professionals who deal daily with the 2019 coronavirus outbreak. Psychiatry Res. 2020. https://doi.org/10.1016/.jpsychres.2020.112972.

9. Lai J, Ma S, Wang Y, Ca Z, Hu J, Wei N, et al. Factors Associated With Mental Health Outcomes Among Health Care Workers Exposed to Coronavirus Disease. JAMA Netw Open. 2020. https://doi.org/10.1001/jamanetworkopen. 2020.3976.

10. Giulia P, Mantas C, Dimitroula D, Mantis D, Hyphantis T. General hospital staff worries, perceived sufficiency of information and associated psychological distress during the A/H1N1 influenza pandemic. BMC. 2010. https://doi.org/10.1186/1471-2334-10-322.

11. Maunder RG, Lancee WJ, Rourke S, Hunter JJ, Goldbloom D, Balderson K, et al. Factors associated with the psychological impact of severe acute respiratory syndrome on nurses and other hospital workers in Toronto Psychosom Med. 2004;66(6):938-42.

12. Styra R, Hawryluck L, Robinson S, Kasapinovic S, Fones C, Gold WL. Impact on health care workers employed in high-risk areas during the Toronto SARS outbreak. J Psychosom Res. 2008;64(2):177-83.

13. Spielberger CD, Gorsuch RL, Lushene R, Vagg PR, Jacobs GA. Manual for the state-trait anxiety inventory. Palo Alto: Consulting Psychologists Press; 1983.
14. Bunevicius A, Staniute M, Brozaitiene J, Pop VJ, Neverauskas J, Benevivius R. Screening for anxiety disorders in patients with coronary artery disease. Health Qual Life Outcomes. 2013. https://doi.org/10.1186/1477-7525-11-37.

15. Maunder RG, Leszcz M, Savage D, Adam MA, Peladeau N, Rose M. Applying the lessons of SARS to pandemic influenza: an evidence-based approach to mitigating the stress experienced by healthcare workers. Can J Public Health. 2008;99(6):486-8.

\section{Publisher's Note}

Springer Nature remains neutral with regard to jurisdictional claims in published maps and institutional affiliations.
Ready to submit your research? Choose BMC and benefit from:

- fast, convenient online submission

- thorough peer review by experienced researchers in your field

- rapid publication on acceptance

- support for research data, including large and complex data types

- gold Open Access which fosters wider collaboration and increased citations

- maximum visibility for your research: over $100 \mathrm{M}$ website views per year

At $\mathrm{BMC}$, research is always in progress.

Learn more biomedcentral.com/submissions 